\title{
Volcanic Unrest Simulation Exercises: Checklists and Guidance Notes
}

\author{
R. J. Bretton, S. Ciolli, C. Cristiani, J. Gottsmann, \\ R. Christie and W. Aspinall
}

\begin{abstract}
When a volcano emerges from dormancy into a phase of unrest, the civil protection authorities charged with managing societal risks have the unenviable responsibility of making difficult decisions balancing numerous competing societal, political and economic considerations. A volcano that is threatening to erupt requires sound risk assessments incorporating trusted hazard assessments that are timely, relevant and comprehensible. Foreseeable challenges arise when the inevitable uncertainties of hazard assessment and communication meet societal and political demands for certitude. In some regions that host volcanic hazards, it would be
\end{abstract}

R. J. Bretton $(\bowtie) \cdot$ J. Gottsmann · W. Aspinall School of Earth Sciences, University of Bristol, Bristol, UK

e-mail: Richard.Bretton@bristol.ac.uk

R. J. Bretton · J. Gottsmann · R. Christie

W. Aspinall

The Cabot Institute, University of Bristol,

Bristol, UK

S. Ciolli · C. Cristiani

Dipartimento della Protezione Civile (DPC),

Rome, Italy

R. Christie

School of Sociology, Politics and International

Studies, University of Bristol, Bristol, UK both realistic and prudent to adopt three working assumptions. The complex legal and administrative infrastructures of risk governance will be largely untested and possibly inadequate. Many volcano observatory scientists, and probably even more risk managers and at-risk individuals/communities, will have inadequate recent experience of the challenges of hazard communication during a period of unrest. And lastly, the scientists may also have inadequate practical experience of the needs and management capacities of the risk-mitigation decision makers with whom they must communicate. "Practice doesn't make perfect. Practice reduces the imperfection." (Beta 2011). If this statement is correct, volcanic unrest simulation exercises (VUSE) have a vital role to play within the complex processes of volcanic risk governance. Consistent with the broad approach of the Sendai Framework for Risk Reduction 2015-30, this chapter argues that practical knowledge of VUSE can and should be analysed and recorded so that key lessons can be shared for the widest possible benefit. This chapter investigates five recent simulation exercises and presents six complementary checklists based upon data, insights and practice pointers derived from those exercises. The use of checklists, supported by guidance notes, is commended as a pragmatic way to create, test and develop acceptable standards of governance practice. 
It is argued here that well planned and executed simulation exercises are capable of informing and motivating a wide range of risk governance stakeholders. They can identify process and individual shortcomings that can be mitigated. Simulation exercises can and should play a vital role in reducing volcanic risks.

\section{Keywords}

Volcanic unrest $\cdot$ Risk governance $\cdot$ Simulations $\cdot$ Exercises $\cdot$ Training $\cdot$ Communication

\section{Introduction}

\subsection{Simulation Exercises and the Sendai Framework}

This chapter is about reconstructions of the evolution of past, and realistic simulations of hypothetical future, volcanic unrest events. They will be referred to as Volcanic Unrest Simulation Exercises (VUSE). A simulation is "a learning experience that occurs within an imaginary or virtual system or world" and involves role-play, which has been defined as "the importance and interactivity of roles in pre-defined scenarios" (van Ments 1999; Errington 1997, 2011; Dohaney et al. 2015). A fuller working description is set out in Sect. 3.1.

The Sendai Framework prioritises mitigation of risks before response and recovery. It also recognises the importance of "building the knowledge of, inter alia, government officials... through sharing experiences, lessons learned, good practices, and training and education on disaster risk reduction" (UN/ISDR 2015, 15). Mutual learning, dialogues and cooperation between risk governance stakeholders are encouraged. The Sendai Framework also identifies a need for quality standards.

The principal purpose of this chapter is to accept the challenge of the goals of the Sendai
Framework and to share knowledge derived from several recent simulation exercises with a wide audience.

\subsection{The Managerial and Scrutiny Dimensions of Risk}

\subsubsection{Managerial Dimension}

When a volcano emerges from dormancy into a phase of unrest, the civil authorities in charge of managing volcanic risks have to make challenging decisions (Fiske 1984; Dohaney et al. 2015). Decisions balancing safety and cost typically must made with limited information (Sparks et al. 2012a, b; Marzocchi et al. 2012; Jenkins et al. 2012) and in real time and under uncertainty, in a context of intense pressure (Marrero et al. 2015, 2 ). While the primary objective is to minimise the loss and damage from any volcanic event, the socio-economic losses resulting from false alarms and evacuations must also be considered" (Woo 2008; Hincks et al. 2014, 2; Donovan and Oppenheimer 2014).

Poorly handled unrest periods cause social, economic and political problems, even without an eruption. Ill-considered responses may facilitate the release of inappropriate advice and emergency declarations, and may lead to unwarranted media speculation and the premature cessation of economic activity and community services (Johnston et al. 2002, 228).

Recent crises, including the 2010 Icelandic Eyjafjallajökull eruption, have highlighted the difficulty of co-ordinating and synthesising scientific inputs from many different disciplines and institutions, and translating these into useful policy advice at very short notice (Harris et al. 2012; Dohaney et al. 2015). Effective communication, collaboration and cooperation are necessary between many expert and technical advisors, emergency management agencies and lifeline organisations (Doyle et al. 2015).

Jordan et al. (2011) have emphasised the need for scientists to have a clear role, a clear and authoritative voice and effective communication skills. The Organisation for Economic 
Co-operation and Development (OECD) (2015) has identified the need for scientific advisers to have: (1) permanent authoritative structures; (2) a central contact point; (3) clear reporting procedures; (4) a pre-defined public communication strategy; and, when necessary, (5) ways to coordinate their actions internationally.

Although civil protection "authorities may have theoretical knowledge of volcanos, few have any practical experience of eruptions" (Solana et al. 2008, 312). Furthermore, the timescales of periods of volcanic unrest, especially bigger ones, do not correlate well with the tenures of political and senior management appointments (Donovan and Oppenheimer 2012; Mothes et al. 2015).

The term 'standard equivocality' relates to the "absence of commonly recognised standards capable of guiding, measuring and evolving acceptable practice" (Hood 1986; Bretton 2014; Bretton et al. 2015; Rothstein 2002). It is suggested here that there are no readily accessible standards regarding how hazard communication should be conducted during a period of volcanic unrest.

\subsubsection{Scrutiny Dimension}

The International Federation of Red Cross and Red Crescent Societies (IFRC) and United Nations Development Programme (2015) (IFRC/UNDP) legal checklist requires national laws to establish and promote the training of public officials and relevant professionals.

There is an emerging international law duty upon sovereign states to have substantive regulatory systems to ensure that risks from natural hazards are mitigated so that they do not endanger human lives. States must inform at-risk communities of the potential of unmitigated risks and establish sufficient co-ordination and cooperation between administrative authorities. This is an onerous duty and it is argued here that it would be prudent to assume that the general duty includes several more specific subsidiary duties. One would be to consider the merits of simulation exercises as a way of satisfying: (1) the specific requirements of national laws; (2) the general expectations of international law; (3) the education, training and knowledge-sharing goals of the Sendai Framework; and (4) the requirements of the IFRC/UNDP legal checklist.

\subsection{Academic Support for Training and Simulation Exercises}

The experience and levels of expertise of observatory scientists are critical to making accurate forecasts and training is important (McGuire and Kilburn 1997). In the context of volcanic risks, Doyle et al. (2015) undertook a review of the literature on emergency management team response, decision making, mental models and situation awareness and exercising. They argue that science agencies and science advisory groups must embark on a suite of training activities to enhance their response during a disaster. These should include exercise and simulation programmes within their own organisations rather than participation solely as external players in emergency management activities. Structures, resources and time must be provided for these programmes.

It is further argued by Doyle et al. (2015) that training will enhance the future response capabilities of both scientists and risk-mitigation agencies in several ways.

\section{Methodology}

This chapter reviews five simulation exercises (four of which were conducted as part of the VUELCO project), which for ease of reference are summarised in Table 1. It investigates the ways in which these exercises were planned and undertaken. By design, it does not address in any detail: (1) the features of the various and varying volcanic settings in which the exercises were conducted; or (2) the nature, scope or analysis of the monitoring data that were painstakingly created for the volcanic hazard scenarios that underpinned them.

This chapter draws from ethnographic observational data (recorded in hand written field notes) collected during five simulation exercises from the perspectives of overt non-participant 


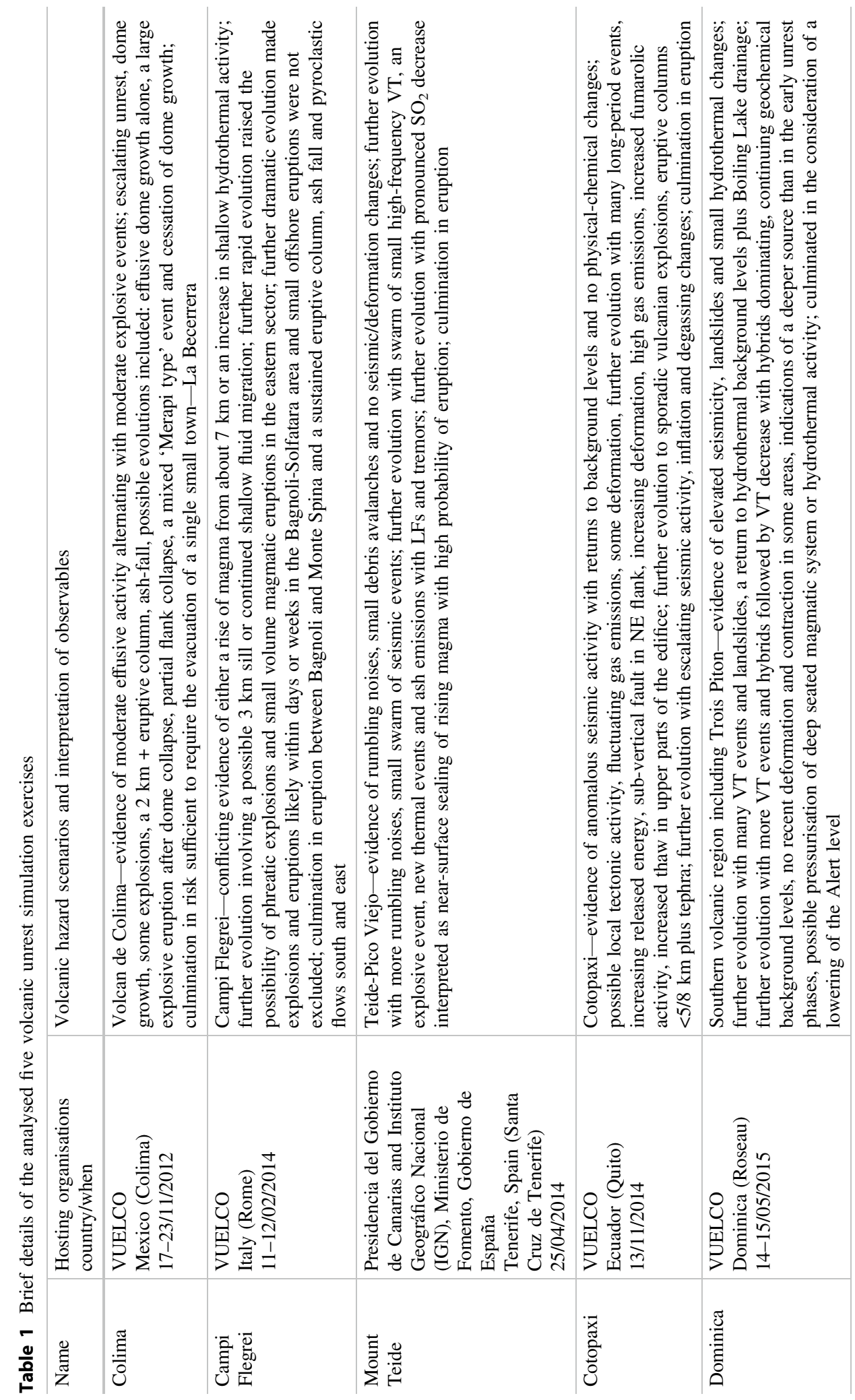


observers and, to a very limited but recorded extent, of participant-observers. Four exercises relate to VUELCO volcano unrest simulations in Mexico, Italy, Ecuador and Dominica. Detailed analysis of the documents prepared before, during and after these exercises was undertaken. The challenges of avoiding researcher bias and unintended observer effects were recognised.

Additional observational and documentary data were acquired by the lead author during the Tenerife (Spain) exercise as an invited external non-participant observer commissioned to prepare a post-exercise evaluation at the request of the Presidencia del Gobierno de Canarias. No ethical agreement was signed before or during that exercise. Data from that exercise and extracts from the post-exercise report are included by kind written permission of the Presidencia del Gobierno de Canarias.

Within the main body of this chapter, no attempt is made to provide complete details of the five exercises listed in Table 1. Essential background information and additional reading sources are to be found in additional files A-E which, for ease of reference, have deposited at the 'Collaborative volcano research and risk mitigation' (VHUB) website under reference "Volcanic Unrest Simulation Exercises: checklists and guidance notes-Additional files A-E". The additional reading sources are also listed at the end of the references for this chapter.

\section{Background}

\subsection{VUELCO Themes and Goals}

As VUSE are purpose-driven learning activities, each will have tailored goals and an overall design based upon the needs of its participants. Consistent with VUELCO's stated goals, the principal purpose of each VUELCO exercise was to present a realistic simulation of the evolution of past and hypothetical future volcanic unrest events associated with a host volcano or wider volcanic setting. In the manner of a film set, a simulated volcanic event is the dynamic backdrop against which a selection of risk governance infrastructures, policies, procedures and people is tested.

The VUELCO exercises involved the provision of raw or partially analysed monitoring data and information to geo-scientists. Their role was to undertake a scientific analysis of the data with the purpose of passing on characterisations of likely volcanic hazard scenarios, by means of hazard communications, to risk mitigation decision-makers (civil protection authorities and the representatives of at-risk individuals) and the mass media. The civil protection authorities, having considered not only societal issues but also political, economic and other values, made and communicated risk mitigation decisions. In some exercises, representatives of at-risk communities, emergency services and relevant government entities played active roles in testing emergency, law and order, rescue, medical and evacuation procedures.

\subsection{Checklists and Guidance Notes}

\subsubsection{Checklists}

The checklists within this chapter are presented in response to the perceived importance of such documents as sources of good practice in the eyes of recent commentators (e.g. Gawande 2010; Newhall 2010; IAVCEI 2015). For example, within the 'Safe Surgery Saves Lives' project, which started in 2007, the World Health Organisation (WHO) introduced a Surgical Safety Checklist developed by Dr. Atul Gawande based, inter alia, upon the success of pre-flight checklists in enhancing safety within the aviation industry. "A systematic review and meta-analysis of the effect of the WHO checklist" strongly suggests a related "reduction in post-operative complications and mortality" (Bergs et al. 2014, 150; Treadwell et al. 2014).

Drawing upon the research of Gawande (2010), this chapter's checklists aim to incorporate several critical features that are output and outcome-focussed. As far as reasonably practicable, the authors' aim has been to ensure that each checklist is: (1) concise and preferably short as well; (2) simple, precise and unambiguous; 
(3) targeted by addressing only evidence-based priorities that are considered either critical or significant to risk governance; and (4) non-prescriptive and non-comprehensive. Checklists may encourage rational, systematic (i.e. both consistent and complete), routine and transparent practices whilst recognising the importance of, and encouraging careful attention to, a wide variety of constraints and expectations. However, it is not envisaged that they should be used as a regulatory device, an enforceable legal requirement, or part of a blame-avoidance strategy (Hood 2011; OECD 2015).

The checklists presented in this chapter address the general planning, funding and execution of purposeful simulation exercises. The exercises also highlighted the many challenges of hazard communication and the difficulties that may result if the needs of other stakeholders are not identified and responded to.

This chapter presents six checklists namely: (1) Planning; (2) Logistics; (3) The Volcano team; (4) The Scientific Advisory Committee (SAC); (5) The Risk Managers - Civil Protection Authorities (CPA); and (6) The Observers/ Auditors. The first two relate to exercise 'phases' and the other four relate to 'roles'. It is not suggested that these checklists will be relevant to all simulation exercises, however, they will provide an indication of some of the critical phases and major roles that must be considered.

The checklists inevitably reflect the fact that VUELCO's exercises placed particular emphasis on the scientific analysis of monitoring data, the communication of hazard characterisations to risk managers, and interactions between scientists, risk managers, the media and the general public. It is accepted that future exercises may have other goals for which more or different checklists may be helpful.

The 'Planning' checklist encourages the identification of goals and objectives, and the need for clear leadership, careful design and realistic financing.

The 'Logistics' checklist is probably the most important. The actual task of arranging the 'planned' exercise may have many benefits in its own right as it will require the careful identification of key laws, policies, procedures and people.

The 'Volcano team' has the very difficult obligation to craft and deliver monitoring data consistent with realistic volcanic hazard scenarios. The data must be suitable to meet the hazard analysis challenges confronted by the experts within the 'Scientific Advisory Committee' (SAC). It is noted here that, in some situations, the roles of monitoring and analysis may be undertaken by the same team or with substantial personnel overlaps. This chapter retains the separation to cover circumstances where there are distinct group remits, functions and responsibilities.

The SAC receives and handles the data provided utilising, as appropriate, a variety of soft skills (including those of analysis, deliberation and communication), tools (including expert elicitation and probabilistic models) and established procedures and protocols.

The 'Risk Managers - Civil Protection Authorities' (CPA) make risk mitigation decisions based in part upon scientific communications received from the $\mathrm{SAC}$ or, where the existence of a SAC is not foreseen within the relevant governance system, the Volcano team. An important part of the CPA role is usually the challenging duty, not only to advise individuals and entities driven by political values, but also to interact with members of the public and respond to mass and social media demands. The press and social media "can play an important role in the dissemination of information, true or false" and social media can rapidly ferment public, anxiety, distrust or dissent (OECD 2015, 37).

Simulation exercises are learning/training exercises and, accordingly, the importance of 'Observers' should not be underestimated. If properly briefed, observers and auditors will not only contribute their own candid views about all aspects of the exercise but also encourage other participants to be reflective about their own contributions and actions.

\subsubsection{Guidance Notes}

To support and supplement the checklists, it is suggested here that guidance notes should be 
issued from time to time to provide a dynamic and helpful knowledge and innovation resource. Their aim should be: (1) to gather together, record and share the accumulated experience of other practitioners in relevant fields of expertise; and (2) to suggest ways to find optimal solutions to the most critical issues.

It is readily accepted that the observations within the guidance notes are inevitably subjective. They are not intended to be in any respect either comprehensive or prescriptive. They are presented as options to be considered along with other issues that will be found within best practice guidelines such as those identified in Doyle et al. (2015).

\section{Checklists (in bold italics) and Guidance Notes (in normal font)}

\subsection{Planning}

\section{Leadership}

Who (individual and entity) has overall responsibility for planning and delivering the exercise?

The choice of exercise leaders should be dictated by the planned goals and activities of the exercise. If a significant involvement of civil protection authorities is planned (for example, where risk mitigation decisions are to be made and/or related mitigation measures are to be tested) those authorities should probably take the lead.

The VUELCO exercises have suggested that overall responsibility for a VUSE should be assigned to just one person within the risk governance stakeholder (e.g. the civil protection authority) likely to gain most from it. That person, who will need suitable and sufficient support from a working team or steering group, should have the gravitas, personality, authority, experience and resources (both human and financial) needed to plan and handle a complex high profile project that will inevitably attract political, societal and media attention.

The MIAVITA Handbook $(2012,118)$ suggest that it is good practice for "a steering group to be in charge of co-ordination and leadership of the various preparatory activities".

After one VUELCO exercise it was suggested that at least "a full-time scientist" should be dedicated to preparing any exercise that focusses on scientific analysis.

\section{Purpose and Goals}

What is the overall purpose of the VUSE?

What are the short and long term goals of the exercise and its players?

A VUSE is a learning activity and the principal reasons for it must be identified and stated. It should respond to the perceived core needs of the participating stakeholders and, like any learning activity, be carefully planned with stated assumptions, aims, objectives and themes.

Before the exercise, each and every participant should know what they will learn from the exercise. Thought should also be given to how and by whom the success of the exercise will be evaluated and what will be done by whom to build upon the exercise.

The assumptions, aims, objectives and themes should be set out in the pre-exercise briefing note referred to in Sect. 4.2 of this checklist.

\section{Scope}

Which parts of the risk governance process are going to be tested?

A VUSE should be focussed, purpose-driven and planned accordingly.

No VUSE can realistically attempt to replicate all aspects and phases of, and all stakeholders interested in, a societal risk governance regime. It is possible that more regular exercises, which concentrate upon very carefully defined aspects of the system (e.g. communicating in real time with the general public and the mass media), may be more cost-effective and beneficial.

Consideration might be given to those issues and functions that require the most inter-stakeholder planning, cooperation and collaboration and accordingly excellent means of communication. A VUSE can and should be a learning exercise in communication between many key players such as: 
- Geoscientists and other geoscientists.

- Geoscientists and risk governance advisers (e.g. weather forecasters, aviation and marine space managers, communication specialists etc.).

- Geoscientists and other stakeholders (e.g. individuals within civil protection authorities, interested and affected members of the public, representatives of community, religious, public utility and commercial interests, and representatives of international, national, regional, municipal and other levels of government).

- Local geoscientists (e.g. volcano observatory staff) and visiting scientists (e.g. academics contributing to a scientific advisory committee) and visiting researchers.

- Hazard analysts (e.g. local and visiting geoscientists) and experts in risk assessment and management.

- All scientific analysts/risk decision makers and (1) the general public and (2) the mass media.

In 1999 several of these interactions were addressed by IAVCEI's Subcommittee for Crisis Protocols, which issued a report entitled "Professional conduct of scientists during volcanic crises" (Newhall et al. 1999). In the context of the governance of the risks of volcanic hazards, this paper represents a rare, if not unique, example of an attempt to offer authoritative practice guidance based on past events and an extensive literature review. It was concerned principally with personal and institutional interactions during a volcanic crisis.

Consideration should also be given to whole or part of an exercise being in 'degraded mode'. The MIAVITA Handbook $(2012,118)$ suggests that exercises should be planned to test system level capabilities of response when some parts of the system are not fully operative. By this means, depending upon which aspects are being tested, allowance can be made for, inter alia, holidays, the malfunctioning or destruction of monitoring or telecommunication equipment, blocked escape or rescue routes, and weather conditions.

By way of illustration of needs that an exercise might seek to target, Exercise Capital Quake identified eleven functions_-'Public Information Management, Governance, National Financial System, Logistics and Other Support Co-ordination, International Assistance and Liaison, Rescue, Health, Welfare, Building Safety, Restoration of Access and Restoration of Lifelines" (NZ/MCDEM 2008).

Another possible example comes from the "Metodo Augustus", the organisation of emergency management, used at the Italian Department of Civil Protection. That organisation provided several support functions including technical-scientific, health and veterinary assistance, mass-media and information, volunteers, means and materials, transportations and mobility, telecommunications, essential services, damage assessment, operational structures, local administrations, dangerous materials, people assistance, cultural heritage and coordination (Galanti et al. 2006).

VUELCO chose a science-orientated focus for its four exercises concentrating upon the interfaces between:

- Hazard monitoring and hazard assessment:

- Long-term monitoring

- The host volcano's main precursors of volcanic unrest.

- The host volcano's short-term monitoring resources (e.g. equipment, employed staff and volunteers etc.), the nature, adequacy and timing of the data output, and their capacity to respond to changing demands.

- Hazard assessment and risk assessment

- As the period of unrest evolves: (1) real time characterisations of the host volcano's possible and most likely hazards and their temporal, physical and spatial parameters; and (2) other advice e.g. the merits/safety of further/different short-term monitoring.

- The communication of scientific analysis (with its inherent assumptions, limitations, complexities and uncertainties) to a variety of stakeholders each possibly having different requirements and expectations and related communication challenges. 
If an exercise focusses predominantly upon scientific issues, it may be very difficult to engage participants from civil protections agencies and more 'risk' related functions.

A VUSE can be a good opportunity to test the processes by which scientific analysis is integrated into risk assessment agencies, such as civil protection authorities, that do not have embedded scientists.

What is the proposed active participant scope?

In a VUSE, if time and resources permit, a wide range of stakeholders can be represented and actively involved including, but not limited to:

- the host volcano as the source of scientific and visual data, which are provided sequentially in discrete pre-planned "phase" briefings/reports (hereinafter called the Volcano team);

- host volcano observatory scientists (the VOS);

- local and external scientists (collectively called the scientific advisory committee or SAC);

- risk assessors and managers possibly from a range of national, federal, state, regional and municipal tiers of government (hereinafter called civil protection authorities or CPA);

- the media;

- interested and affected members of the public.

In a more sophisticated exercise, it may be worthwhile ensuring that a "dissenting/minority view" and/or "maverick" scientists are represented to test robustly relevant democratic and communication processes.

The MIAVITA Handbook (2012, 114-116) details the benefits of informing, sharing and training involving: (1) national, regional and local authorities; (2) scientists; (3) volunteers; (4) the media; (5) pupils and students; and (6) the public.

The VUELCO Colima exercise incorporated the planned evacuation of an at-risk community. A VUSE can usefully focus upon the real time implementation of the risk mitigation strategies that result from the dynamic characterisation of an evolving unrest. However, the time and resources required to identify and engage multiple stakeholders, including members of the public, should not be underestimated.
Care must be exercised if one of the hazard scenarios will result in the need for the evacuation of representatives of at least one vulnerable community. Of course, this will have to be organised and announced well in advance of the start of the exercise. This may affect (i.e. make rather implausible) other parts of the exercise which may depend upon realistic and continuing uncertainty as to the future evolution of the initial hazard.

What is the proposed passive participant (e.g. observers and monitors) scope?

In the VUELCO exercises, very valuable contributions were made by monitors and observers. They can be from the participating organisations or entirely 'independent'. Monitors and observers (particularly with experience of previous exercises and the practices of countries other than the host country) can play a critical role in providing both hot and cold feedback whilst also gaining invaluable personal experience to assist in the planning of future exercises.

VUSE are invariably observed by local and visiting students and early career academics. With careful planning, it may be possible for less experienced scientists and civil protection authority decision makers to be involved directly (as happened in the Campi Flegrei VUSE) or indirectly in the 'shadow' SAC and CPA teams.

Reference should be made to the separate Observers/Auditors checklist in Sect. 4.6.

\section{What is the proposed geographical scope?}

The geographic scope of a VUSE should be considered carefully. A balance must be achieved between the spatial parameters that produce a risk exposure area that is realistic in the context of the host volcano and those that create an area that is too large in terms of the duration of the exercise, data production and/or the roles of the active participants.

\section{What is the proposed administrative scope?}

National laws tend to identify, authorise and fund risk governance bodies (e.g. government departments and agencies, public corporations) and public officials (e.g. individuals such as governors, mayors, prefects and village heads) within a coherent legal and administrative framework-a risk governance infrastructure. 
These laws often use and build upon existing entities with existing administrative frameworks that have multi-level national, regional, district, municipal etc. political divisions and subdivisions (Bretton et al. 2015).

The MIAVITA Handbook $(2012,118)$ suggests that it is good practice for an exercise to "be based on the regulations and laws of the [host] country".

The administrative scope of a VUSE should be considered carefully and it is likely this scope will be related to those parts of the risk governance process selected for review and testing. It may be very difficult to involve actively all levels of governance and therefore a decision will have to be made as which levels will participate and which will merely observe.

It is likely that a good starting point will be a complete flow diagram of the existing societal risk governance infrastructure for the host volcanic region. This can then be annotated to indicate which national, regional, local bodies and individuals will participate and their respective roles (both active and passive) in the exercise.

For the SAC and CPA at least, consider setting out clearly its respective:

- legal status;

- legal remit and reporting lines; and

- the rights, responsibilities and liabilities of its members.

\section{Duration and type}

\section{How long will the exercise last and why?}

This is a very important issue with funding, resources, logistical and many other implications.

VUSE vary greatly in length as shown by the data in Table 1. Much will depend upon the critical decisions that must be made about scoping - process, participants, geographical area and administrative levels.

\section{What type of exercise will be undertaken and} why?

There are many types of management exercises including: (1) full-scale; (2) reduced; (3) orientation; (4) drill; (5) table-top/discussion; and (6) functional (see Doyle et al. 2015).

Exercises can be also announced or unannounced depending upon their objectives. It has been suggested that the use of unannounced exercises is necessary to verify the real strength of systems and levels of preparedness, when people do not expect them (MIAVITA 2012, 116-117)

\section{How frequently should exercises be held?}

The MIAVITA Handbook $(2012,116)$ notes that exercises are fundamental for testing existing procedures, plans, and preparedness and for maintaining the attention of stakeholders "on the spot". It also argues that exercises should be scheduled frequently with the frequency depending upon several factors including: (1) the behaviour of the host volcano; (2) the social-economic context; (3) the levels of risk perception; and (4) the democratic trend.

\section{Finance}

What are the planned budgets for all phases of the exercise including:

\section{- Before?}

Consider planning, field trips, printed field guides, data and scenario creation, documentation etc.

\section{- During?}

Consider venue, catering, data/scenario communication etc.

\section{- After?}

Consider feedback (hot and cold) and follow up meetings, reports, presentations, interviews, actions. 


\section{Who is funding:}

- The exercise?

- The participants, including invited guests, experts and invited observers/auditors (including travel, accommodation, field trips, other expenses etc.)?

Consider whether there should be an underwriter of last resort for any unplanned deficiencies.

Do the funders have any demands, expectations etc. as to any aspects of the exercise?

If yes, these must be understood by the organiser, planned and budgeted for.

\subsection{Logistics}

\section{How long will the planning stage take?}

It would be easy to underestimate the time that will be needed for, and the complexity of, the planning stage upon which the whole success of the exercise will depend. It may be prudent to speak to the organisers of other VUSE to discuss this and other financial/practical issues. Reference could also be made to Dohaney et al. (2015).

The MIAVITA Handbook $(2012,118)$ notes that planning an announced exercise takes time and states "six to twelve months are necessary to prepare a full-scale exercise. If the promoted exercises are repeated on a fixed schedule, three can be sufficient". We consider these to be the minimum planning periods.

Will every participant/observer receive in advance a full briefing note covering:

\section{- Purpose}

Refer to the Sect. 4.1 regarding the overall purpose of the training exercise.

\section{- Scope}

Refer to the Sect. 4.1 regarding scoping. Issues covered may include processes, participants, geographical, administrative etc.

\section{- Themes}

If some important themes have been identified for particular attention (e.g. expressions (numerical and narrative) of likelihood, expressions of analytical/diagnostic confidence, dealing with communication network failures, using social media etc.), it might make sense to mention these in advance to encourage pre-exercise thought and preparation.

\section{- Models, methods and protocols to be used/made available for use}

The VUELCO exercises have proved that VUSE can be used successfully to test in simulated real time the merits of probabilistic methods and tools such as BET_EF (Bayesian Event Tree for Eruption Forecasting), HASSET (Hazard Assessment Event Tree) and QVAST (Quantifying Volcanic Susceptibility) (Sandri et al. 2009; Sobradelo and Bartolini 2014; Bartolini et al. 2013).

In advance of the exercise, there must be communication between the modellers and the Volcano team. This should ensure that all appropriate monitoring data (perhaps deliberately not all the data) is available for all relevant phases of the exercise scenario including periods between phases.

Feedback from the VUELCO exercises suggests that input from the modellers during each step of an exercise may be welcomed by other participants. Testing simultaneous integration was a specific VUELCO goal. However, if this is to be done, it must be carefully planned and sufficient time allocated within the timetable.

It is important to state in advance of the exercise, for example in the briefing documents, what role the models, tools etc. will play during the exercise. Consideration should be given to whether the results will be available in real time to the participating SACs and CPAs. If yes, how and when will the results be communicated? If no, when will feed back regarding the utility of the items tested be communicated?

VUSE can also be used to give SAC's the opportunity to use formal expert elicitation (EE) methods. EE may provide formality and direction to the deliberation of monitoring data, assist the framing of likely hazard scenarios, and facilitate the drafting of expressions of temporal certainty and analytical/diagnostic confidence. 
EE were conducted in the VUELCO exercises in Colima and Campi Flegrei.

The Somma Vesuvio MESIMEX exercise undertaken in 2006 was used to conduct a before and after volcanic risk perception survey (Ricci et al. 2013).

\section{- Players (participants, observers etc.): \\ - by name and organisation \\ - by role in the exercise}

It is very likely that a large number of people will be involved from a wide range of organisations and, perhaps, several countries. It would be prudent to assume that nobody will be known to all of the other participants. Consider the use of name badges stating Name, Organisation, and Exercise Role. As found during the Campi Flegrei exercise, colour coding for teams and active/passive roles might also be helpful. The scheme adopted should be explained carefully to save time during the start of exercise when valuable time can be lost easily.

By way of illustration, more than 100 participants from over 10 European and Latin American countries attended the VUELCO Campi Flegrei exercise. The respective figures for the VUELCO Cotopaxi exercise were about 50 participants from 13 countries.

After the Dominica exercise it was suggested that, at the very start of the exercise, introductions would have been helpful "to establish who each person was and what their role was...It was challenging accepting information from a person whom we did not know or have any clue as to their background or capabilities. Also the scientist [s] must be aware of who the[y] are working with in order to frame their advice appropriately".

For numerous purposes (before, during and after the exercise) a comprehensive, up-to-date and accurate email list containing all participants will be necessary. Inadequate email lists caused difficulties during several VUELCO exercises.

\section{- Teams}

Consider how many teams will be required and how and when their members will be allocated. For the sake of simplicity, it may be necessary to ask representatives of several different organisations to work together. By way of illustration, this chapter refers to four teams (Volcano, SAC, CPA and Observers) but others can and should be used as dictated by the specific goals of the planned exercise.

Consideration should also be given to the use of a technical team to support the SAC's deliberations in respect to issues such as real time GPS mapping, model trials and expert elicitations. The time needed for these complex matters must be considered particularly during short exercises. In VUELCO's Campi Flegrei simulation, a technical team composed of civil protection personnel operated continuously with the aim of supporting the SAC's simulated 'real-time' deliberations. The team's results were only presented at the end of the exercise because they lagged behind the 'real time' evolution of the phases of the exercise's hazard scenarios.

\section{- Venue (full address, plan, transport and contact details) \\ - Sub-venues for all aspects of the exercise (including any evening events) with a plan \\ - Layout for the plenary sessions \\ - Layout for any breakout sessions}

These critical issues should not be overlooked. The exercise organiser should decide in advance, in respect for each phase of the exercise, which 'team' will sit where and why, probably by reference to which other participants they will have to communicate with. For the sake of intended realism, consider whether they should be near or far apart and by what means they will communicate.

Consider whether, in a real emergency, participants would speak to each other face to face. Consider whether it would be more realistic to separate some teams physically in order to force the use of video conferences, emails and phone calls in team interactions. At the planning stage it will be necessary to allow more time for this nuance, which may highlight the challenges of long-distance communication, data sharing, data analysis, collaboration, consensus building and decision-making. 
Feedback from the VUELCO exercises specifically mentioned the problems associated with having too many people in the same room and failing to plan in advance who should be where and near to whom.

It is worth considering that each refreshment break will take longer than expected unless refreshments are either provided in all rooms or available at all times. Will working lunches simulate the difficulties of a tense period of emerging unrest? For a short period of intense training, is a degree of inconvenience and/or discomfort in fact to be encouraged?

\section{- Timetable}

- Dates for each part of the exercise and timings for each day addressing:

- Registration (including perhaps the handing out of name badges in accordance with the stated scheme)

This will need very careful planning and resourcing to avoid a late start on Day 1.

- Start, finish

Start and finish promptly.

- Food/drink breaks (if needed!)

Refer to the above guidance about the need for these in an exercise that attempts to simulate real time challenges.

\section{- Evening events, banquets etc.}

Consider how long it will take participants to return to their accommodation before evening events. Give clear advice about the dress code, if any, and other cultural expectations (e.g. the use of cameras or the need for modest clothes and head coverings).

\section{- Venue tours}

It is likely that many of the participants will expect/request a tour if the exercise takes place in a major risk management/communication centre. Allow plenty of time for this and consider making these visits part of the pre-exercise field trip to avoid wasting time when all of the participants (and probably the media) are present.
- Greetings, Introductions, Reviews, Thank you's etc.

- Presentations to or by representatives of central, local government, etc.

Predicting accurate timings for these two components is notoriously difficult and careful planning in advance and strict control on the day will be necessary. Consider carefully whether these are really necessary. Consider whether it would be better for relevant entities to be given formal active or passive roles within the exercise itself and be appropriately involved in that way.

\section{- Dissemination of new data}

Consider when, by whom, to whom and how. During the VUELCO exercises, difficulties arose due to format incompatibilities and internet access issues.

\section{- Deliberation of new data}

The time necessary for deliberation may depend upon the amount/ format of the data, the need to communicate with other participants, expectations about output deliverables (e.g. written reports) etc. As a general rule, allow plenty of time within the context of the realism that the exercise seeks to simulate.

\section{- Dissemination of 'injects'}

Consideration should be given to the timing and drafting of 'inputs' (for example, requests for local, national and international media interviews or briefings with concerned public officials, unwelcome social media exchanges, etc.), which will be distributed to the participants at planned stages during the exercise. Participants might be asked to think about how they would respond and who would be delegated to meet these urgent requests.

\section{- Outputs from the SAC and other teams}

As a general rule, allow plenty of time for the dissemination of outputs within the context of the realism that the exercise seeks to simulate. 
Will information about current CPA mitigation actions, risk alert levels etc. be provided at any time during the exercise?

If yes, why, what, when and to whom?

Feedback from the VUELCO exercises suggests that scientists benefit greatly from improved knowledge of civil protection authority systems and in particular better appreciation of those hazard parameters that are most relevant to risk mitigation decisions.

\section{- Factual background and related resources}

Consider whether a field trip is necessary before Day 1 of the exercise so that all of the participants can gain a basic grasp of the topography, geography, geology (including major structures, faults, tectonic plates, existing volcanic and other hazards, and aquifers), geo-history (a time-line of major events is often helpful), infrastructures and other essential information.

All the VUELCO exercises incorporated well-planned and informative pre-exercise field trips that were supported by printed, carefully researched field guides with relevant histories, maps, reading lists etc.

A field guide can be supplemented by more detailed essential information about the monitoring history, thresholds etc. Feedback from VUELCO exercises suggests that the briefing pack should include maps showing the positions of all relevant observatories, monitoring equipment and stations, GPS positions, cameras, sample sources etc.

In addition to a field trip, it may be helpful to have a day/half-day of short presentations about the host volcano with careful oblique references to features that will be relevant during the exercise.

\section{- Real/assumed legal/regulatory framework and related duty holders}

Each participant must have a clear and comprehensive understanding of their role, the roles of all other participants and all planned lines and methods of communication. To ensure a higher degree of realism, these roles should accurately reflect the governance infrastructures, roles and duties required by:

- the national laws of the host country as encouraged by the UN Sendai Framework and the IFRC legal checklist;

- any regional emergency management or response arrangements, such as those in the Caribbean involving the Caribbean Disaster Emergency Agency (CDEMA), which are set out in inter-country agreements, memoranda of understanding and protocols; and

- any applicable international law standards.

\section{- Information Technology (IT) including disseminating/sharing data*}

This critical issue should not be underestimated based upon difficulties encountered during VUELCO exercises.

It is inevitable that most of the participants will wish to have easy access to the internet. Ensure that the Wi-Fi network has sufficient capacity and range to allow easy access.

Consideration should be given to the format requirements of the computer models and probabilistic tools that will be tested during the exercise.

\section{- Language arrangements*}

Consider the dominant language for the exercise and its documents (particularly the pre-exercise briefing pack) and what arrangements can be made, if any, for translations/translators.

Feedback from the VUELCO exercises suggests that some participants (e.g. locally based risk managers and members of the emergency services) may become bored and disengaged if they cannot understand fully what is going on and contribute.

\section{- Other equipment*}

Consider whether it will be necessary, for the purposes of training, publicity or planning future exercises, to use other equipment including:

- Display screens, smart boards and white boards 
- Fixed and roving microphones

A shortage of roving microphones caused irritation at several VUELCO exercises.

- Visual and audio recording equipment

- A projector for PowerPoint presentations Feedback sessions are enhanced by such presentations, if time allows for their preparation.

- Laser pointers

- Video conference links

\section{- Presentations of data, results etc.*}

How, why and when will the data, results etc. be presented?

Consider imposing a strict timetable to avoid timing problems.

\section{- Requirements regarding pre-Day 1 reading,} preparation, queries etc.

Consider stating clearly that there will no lengthy introductions or briefings at the start of Day 1 because the participants are required and expected: (1) to read in advance the pre-exercise briefing pack; and (2) to raise any queries before Day 1 with the exercise organiser.

\section{- Procedures for daily and end of exercise feedback.}

If daily feedback or announcements are necessary, consider in advance what issues are likely to be covered, who will give them and allow adequate time within the timetable.

\section{*Note}

It is accepted that during a real emergency these facilities may not be readily available. Accordingly, any difficulties encountered during an exercise may provide helpful insights into the challenges that would be encountered during a fast evolving crisis.

Will role/team leaders receive in advance?

- A full pre-exercise briefing note about the overall legal/regulatory infrastructure for the exercise?
- Checklists for the main aspects of the exercise?

\section{Day 1 (Start of exercise)}

Ensure that registration does not delay a prompt start, which will thereby set the standard for all other timings during the exercise.

Who will lead the exercise and ensure that the timetable is adhered to strictly?

Consider giving this role to a person (probably supported by an assistant) who does not have any other role in the exercise and therefore can move easily from room to room and deal promptly with any difficulties that arise.

Is there a need for a short introduction? If yes, why, who will give it and how long will it last?

Is there a need for a short end of day summary? If yes, why, who will give it and how long will it last?

\section{Day 2 etc. (Continuation of exercise)}

Is there a need for a short introduction? If yes, why, who will give it and how long will it last?

Is there a need for a short end of day summary? If yes, why, who will give it and how long will it last?

\section{Day (End of exercise)}

Is there a need for a short introduction? If yes, why, who will give it and how long will it last?

Is there a need for a short end of exercise summary? If yes, why, who will give it and how long will it last?

\subsection{The Volcano Team}

\section{Membership}

Who will lead the team and why?

Who will be the other Volcano members?

VUELCO's exercises indicated that considerable time, exceptional skills and infinite patience are required to write any coherent and challenging hazard scenario.

Members of the Volcano team must: (1) be selected and appointed at a very early stage in the planning process; and (2) be aware of, understand and accept the needs and goals of the exercise. 
The overall hazard scenario and its planned phases must be tailored to fit within the agreed timetable for the exercise. The Volcano team will need to work very closely with the exercise leader and the steering group as soon as it is formed.

Where the Volcano team is the host volcano's actual monitoring team, a chance to test the monitoring team in 'real time' action will be lost.

\section{Preparation}

How long will be needed to prepare:

- the scenario/s?

- all of the briefing documents?

- the pre-exercise field trips?

\section{The exercise}

What will be the time scale in months/years covered by the exercise?

VUELCO's exercise scenarios varied greatly in length-Colima (2 months), Campi Flegrei (7 years), Cotopaxi (5 years) and Dominica (2 years).

The period of time covered by the simulation, the number of phases and the length of the intervals between the phases, must take into account the needs and goals of the exercise. For example, consideration must be given to the time that will be required for data to be delivered, entered and assimilated, and for probabilistic models to be run.

How many exercise phases will be needed to cover the period of years chosen?

Each phase will involve, and must be allocated sufficient time for, the delivery, entry, analysis and modelling of the monitoring data and the drafting and delivery of any expected outputs (e.g. reports, press releases etc.).

VUELCO's exercise scenarios had between 3 and 6 phases - Colima ( 2 months in 4 phases over $10 \mathrm{~h}$ spread over 5 days), Campi Flegrei (7 years in 4 phases over 3 days), Cotopaxi ( 5 years in 6 phases in 1 day) and Dominica ( 2 years in 3 phases over 2 days).

As already stated, the precise specifications for the phases must be agreed with the exercise leader taking into account the needs of the modellers and other technical teams.

\section{What data will be provided?}

The monitoring data must be suitable and sufficient to test the whole range of geo-scientific disciplines represented in the SAC. Feedback from the VUELCO exercises identified the temptation to favour the overprovision of seismic data at the expense of adequate geochemical, geodetic, petrological and other data.

Although this might reflect real situations or even the architecture of existing monitoring networks, careful consideration should be given to the consequences of having experts from some disciplines having insufficient data to occupy them and therefore becoming disengaged from the exercise.

It may also be necessary to provide in the briefing pack related historical data and background information (such as historical thresholds) to allow the data used during an exercise to be considered in context.

The data must remain coherent, albeit deliberately unclear and uncertain, over the full duration of the scenario including periods of inactivity. Feedback after the Dominica exercise praised the quality of the data and the design of the scenario. The following expressions illustrate some of the features of a successful scenariovery realistic unsure signals creating a state of limbo, non-linearity, phreatic evidence that was not a precursor of magmatic activity, complex data and realistic missing data.

During some phases of the exercise scenario it is possible that the data will be incomplete (some critical data may be held back deliberately to await a request for more data) and/or difficult to analyse because it may be a stated objective of the exercise to test the SAC's ability to handle uncertainty, disagreement, monitoring inadequacies etc. and/or to request data from additional or different monitoring.

If data is provided for the periods between scenario phases, it is likely that the longer the inter-phase period the more complete the data will be. Time will have to be planned for data delivery and analysis. A large amount of data may also create very great difficulties for the utility of probabilistic tools such as BET. 
The Volcano team should communicate with the exercise leader and modellers well before the exercise to avoid unnecessary surprises regarding the format and quantum of the monitoring data and the timing of their release. In the Colima exercise, three BET nodes were passed before Phase 1 of the exercise scenario and this degraded the utility of the BET trial.

How will the years between the periods that are covered by the data be described?

This difficult issue should not be overlooked. In the absence of data, what will the participants assume in absence of guidance? An absence of data may also create very great difficulties for the utility of probabilistic tools such as BET.

Consider issuing, along with the monitoring data for the next phase, a brief summary of the 'missing periods' in terms of volcanic activity, precursor evidence and/or the risk mitigation decisions and actions of civil protection authorities.

Will the exercise scenarios be (1) entirely fictitious; (2) based on suitably disguised real events; or (3) a mix of the two?

During the VUELCO exercises feedback suggested that:

- it may be very difficult to create realistic scenarios that are entirely fictitious because the data, under the very close expert analysis that they will receive, may appear to be inconsistent and improbable;

- a coherent and plausible chronology for the scenario is essential;

- after a period of sudden emerging unrest, a period of reducing unrest or quiescence may form the basis of a challenging scenario as proved during the Dominica exercise;

- in order to simulate reality, the Volcano team should provide monitoring data to the SAC without any form of analysis or interpretation, however the provision of tables comparing data sets may be helpful;

- the amount, relevance and format of the monitoring data provided should be considered carefully.

Will the exercise introduce secondary hazards (e.g. forest fires, contaminated aquifers, etc.)?
During the Mount Teide exercise, considerable attention was paid to secondary hazards. If secondary hazards are to be included, what data need to be provided before, at and after the start of the exercise?

Will plans be needed showing geographical, geological or societal features?

Will the exercise use fixed/dynamic data about weather, ground conditions etc.?

If yes, what data need to be provided before, at and after the start of the exercise? Will plans be needed showing geographical, geological or societal features?

Relevant weather/ground water data will be essential if ash dispersion and fall-out simulations are to be included within the exercise.

When, how and to whom will the monitoring data be disseminated:

- Before the start of the exercise?

- At the start of the exercise?

- During the exercise?

This is a critical issue and important lessons were learned during the VUELCO exercises. During a VUSE, reliance on a limited Wi-Fi link may be very problematical.

In the Dominica exercise, monitoring information was provided within separate 'phase-specific' documents in password-protected pdf format and emailed before the start of exercise to all of the participants. At the beginning of each scenario phase, the relevant password was released. This solution worked very well.

During the Cotopaxi exercise, Wi-Fi and other communication difficulties were identified by the civil protection authorities and, as a result, they were better placed to improve their existing systems and resources.

Consideration should be given to the format requirements of the computer models and probabilistic tools that will be tested during the exercise.

Feedback from the VUELCO exercises suggests that when data are provided they should not duplicate data that have already been provided. 
Will the SAC be able to ask for further monitoring data?

If yes, when and how can it be requested? If yes, when and how will it be provided?

Will any player other than the SAC be able to ask for monitoring data?

If yes, by whom, why, when and how can it be requested? If yes, when and how will it be provided?

Will anything other than monitoring data be provided?

Consider whether the SAC and CPA should be given, or have access to when they request it, fixed/dynamic data about weather, ground conditions etc.?

If yes, why, what, when and to whom?

\subsection{The Scientific Advisory Committee (SAC)}

\section{Is a SAC necessary in every exercise?}

Careful consideration should be given to this important question. It is appreciated that advice to civil protection authorities may only be provided by the head of the local volcano observatory, who is not, and would never be supported by a SAC.

Feedback from VUELCO exercises suggests that it makes good sense for exercises to simulate existing risk governance structures as far as reasonably practicable. It follows that a SAC team should be included in an exercise only: (1) where one exists, or could exist, in a period of evolving unrest or (2) where the civil protection authorities wish to test the utility of one.

If an exercise SAC is simulating the actions of a real SAC, the brief to the SAC and the briefing note for the exercise should set out clearly the SAC's constitution, mandate, responsibilities and powers.

\section{Legal status and duties}

A VUSE can be a good opportunity to consider the legal status of scientific committees and their full-time, part-time and seconded members.

Consideration should be given to the taking of appropriate steps to avoid or reduce managerial risks by the inclusion of disclaimers and exclusion statements in hazard assessments. A VUSE may serve as, at least, a prompt for committees to seek legal advice from a competent local lawyer.

During the Dominica exercise, a member of the Scientific Advisory Committee sought legal advice from the lead author about: (1) the wording of a liability disclaimer for the benefit of visiting scientists; and (2) the way in which 'risk-related' advice could be passed to civil protection authorities without liability for subsequent risk mitigation decisions. In respect of the first, it is likely that a visiting scientist will have little or no control in respect of either the absence or adequacy of monitoring data and the selection and competence of other committee members. Based upon this advice, a disclaimer was included in the Phase 1 hazard assessment report and the Phase 2 and 3 reports were more carefully worded.

\section{Membership}

Who will be leading the SAC and why?

The SAC will require a leader who should be identified in advance.

Feedback from the VUELCO exercises suggests the role of Chairperson of the SAC may be critical to the success of an exercise.

Consider whether a deputy Chairperson should be identified in advance of the exercise.

In several of the VUELCO exercises, it became evident that the Chairperson should not be given, or retain, prime responsibility for the initial drafting of the hazard assessment report.

Who will be the other SAC members?

Consider whether it is desirable to have a range of experts to simulate the issues that might arise during a real period of emerging unrest. Consider the inclusion of: (1) local volcano observatory scientists; (2) other host country scientists; (3) host country academics (4) non-national observatory scientists; (5) non-national academics; and (6) young researchers.

The involvement of non-local and foreign scientists may represent an opportunity to share knowledge and to have access to a wider range of opinions uninfluenced by local social contexts, non-scientific values or entrenched scientific assumptions or preconceptions. 
Consideration should be given to the need for rules regarding the nature and extent of the interactions between local and non-local/foreign scientists.

During the Campi Flegrei exercise a number of young researchers were co-opted in rotation onto the SAC. This worked well and gave them a unique learning experience.

Which geoscience disciplines (e.g. geophysics, geochemistry, geodetics, geo-history, and petrology) will be covered within the SAC?

If the monitoring data resources of the host volcano permit, ensure that the Volcano team provides sufficient monitoring data to keep each discipline engaged and, if possible, challenged throughout the exercise.

Will any geoscience disciplines not be covered? Why?

Consider whether this is a realistic representation of what might happen in a real period of emerging unrest.

Will the SAC have local members who are usually based near or at the host volcano?

Consider whether the briefing pack should refer to the IAVCEI protocol mentioned above.

Will the SAC have international members who are not based in the host country?

Consider whether the briefing pack should refer to Newhall et al. (1999) mentioned above.

Will the SAC be realistic in size, too big or too small?

Will any attempt be made to deal with the issue of 'maverick' scientists?

If yes, how? If no, why?

A VUSE may present a good opportunity to consider and test procedures for dealing very difficult issues such as this.

\section{Inputs}

When and in what format will the SAC get the monitoring data?

This is a critical issue. During a VUSE, reliance on a limited Wi-Fi link may be very problematical.

Will the SAC be able to ask for further monitoring data?

If yes, when and how can it be requested? If yes, when and how will it be provided?
Will the SAC get anything other than monitoring data?

Consider whether the SAC should be given, or have access to on request, fixed/dynamic data about weather, ground conditions etc.?

If yes, what data need to be provided before, at and after the start of the exercise? Will plans be needed showing geographical, geological or societal features?

\section{Deliberations}

Will the SAC's meetings/deliberations follow standardised operating procedures (SOPs) and/or use a standardised reporting template?

Feedback following the Dominica exercise advocated the use of SOPs and the keeping of a log recording and timing, inter alia, main data inputs and analytical decisions, assumptions, outputs and communications.

Careful consideration should be given to the SAC adopting working assumptions that:

- All hazard communications, including all hazard assessments, in their format, content and delivery must be focussed upon: (1) facilitating informed risk mitigation decisions that may not only be difficult but also based upon many sources of knowledge and social, political, economic and other influences; and (2) responding to the identified needs and expectations of their makers.

- Before acting as hazard communicators, hazard analysts must (by means of active and careful two-way dialogue) canvass, note and respond to the needs and expectations of the risk decision makers and the legitimate foreseeable demands of mass and social media and allow sufficient time to do this.

- The utility of hazard communications (i.e. the outputs of hazard analysis) must be judged by empirical evidence of the sentiments and actions of risk decision-makers (i.e. the outcomes of hazard analysis within wider risk mitigation processes).

- No assumptions will be made as to what risk decision-makers know about: (1) the science of volcanic hazards and in particular its complexities, uncertainties and limitations; 
(2) the role of scientists and the many temporal, financial, legal and other constraints under which they operate particularly during periods of emerging volcanic unrest; and (3) the role, benefits and limitations of long-term and short-term monitoring.

- No assumptions will be made about what risk decision-makers either need or want and, accordingly, the widest possible range of reasonably practicable options for not only hazard communication but also hazard analysis should be offered and discussed.

- No assumptions will be made that risk decision-makers know what general and/or bespoke analysis, information, data, advice and guidance scientists may be able to provide if asked and given adequate resources.

Will any guidance be given as to how the data should be considered (e.g. expert elicitation, probabilistic tools etc.)?

If an expert elicitation is a possibility or is actively encouraged/required, timetable enough time for this as it is likely that a briefing will be necessary before the elicitation starts to ensure that everyone is fully aware of what will be involved. Do not underestimate the amount of time that a worthwhile elicitation will take.

Consider providing essential information in the form of an elicitation toolkit in advance. Who will prepare this toolkit?

Can the SAC take into consideration any societal factors such as high societal exposure in a particular area? If yes, what 'exposure' and 'vulnerability' data will be provided, when and how? Do not underestimate the amount of time that this will take.

Consider how and when the results of probabilistic models will be delivered to the SAC and thereafter considered. Do not underestimate the amount of time that this will take.

Feedback after VUELCO's Dominica exercise showed that scientists involved in exercises need to be briefed about: (1) the claimed benefits offered by the probabilistic models being used; (2) their limitations; (3) when and in what form their results will be presented; and (4) how it is envisaged their results will be integrated within the overall analysis of relevant hazard scenarios.

Consider including in the pre-exercise briefing pack an additional file containing essential background information about expert elicitations and modelling.

Will the SAC have to liaise with any non-SAC players?

If yes, when and how will this be done?

During the Dominica exercise, sub-team leaders of the SAC were asked to attend early parts of the CPA's deliberations. In the post-exercise feedback, it was suggested that all of the SAC scientists would have benefitted greatly from hearing the CPA's deliberations which were often very critical of the scientific analysis upon which risk decisions had to be made.

\section{Outputs-Hazard communications}

What outputs (e.g. oral and written reports, written minutes etc.) will be required from the SAC?

The quality of the dialogue between risk management stakeholders, and the provision of information and advice, depends upon a mutual understanding by those stakeholders of their respective needs, responsibilities, functions demands and roles, and their capacity to anticipate other stakeholders' demands and decision needs (Salas et al. 1994; Ronan et al. 2008; Lipshitz et al. 2001; Paton and Jackson 2002; Doyle and Johnston 2011a, b; Doyle et al. 2014).

"Without knowing the concerns" and understandings "of the targeted audience, communication will not succeed" (Renn 2008, 147).

Careful consideration should be given to this critical issue. Based upon the VUELCO exercises, it may be very unwise to provide any guidance whatsoever as to how the outputs of the hazard analysis must be communicated to the CPA and other exercise participants. This may encourage the type of two-way dialogue referred to under the above heading "Deliberations". By providing guidance of any sort, a unique learning opportunity may be lost.

Consider briefing the observers in advance about this important issue, so that they can make 
an early invention if unwarranted assumptions are made about what risk decision makers know, need or want.

Will the SAC be required to communicate with teams representing:

- The CPA?

- The public?

- The media?

- Representatives of local/central government?

If yes, when and where?

A VUSE is a good opportunity to practise hazard communications and to consider the needs and expectation of risk decisions and their makers. Reference should be made to Doyle et al. (2015).

Consider how, when and by whom the needs and expectations of risk decision-makers will be sought.

\subsection{The Risk Managers-Civil Protection Authorities (CPA)}

Role

It is critical for the role of the CPA to be considered very carefully during the planning stage.

Feedback from the VUELCO exercises suggests that the CPA's role must be:

- clearly defined and integrated within the design of the hazard scenario;

- sufficiently interesting and demanding to keep the participants engaged; and

- known to all other participants.

The geoscientists will be engaged predominantly with the prompt analysis of monitoring data and this will lead subsequently to the delivery of hazard assessments in some form to the CPA. Depending upon the goals of the exercise, it is likely that, whilst this is being done, the CPA team must have something worthwhile to do.
Consideration might be given to a requirement within both the briefing pack and the timetable that representatives of the SAC discuss with the CPA:

- the timing, format, content etc. of hazard reports, communication channels and protocols (the preparation of a template was suggested after the Campi Flegrei exercise), and/or

- the arrangements for a possible mock joint press conference later in the exercise. A joint press conference might involve another press/media team (possibly made up of individuals from the CPA's public relations department) and/or invited observers from local and national press organisations.

\section{Membership}

Will the CPA represent a real/fictional entity?

Who will be leading the CPA and why?

Who will be the other CPA members?

\section{Inputs}

What inputs will the CPA get?

Will the CPA get monitoring data?

If yes, why?

\section{Deliberations}

Will any guidance be given as to how the CPA inputs should be considered?

Will the CPA have to liaise with any non-CPA players?

If yes, when and how will this be done?

\section{Outputs}

What outputs will be required from the CPA? Will the CPA be required to communicate with teams representing:

\section{- The SAC?}

- The public?

- The media?

- Representatives of local/central government?

A simulated press conference, which involves both scientists and CPA officials within the same 
panel, can serve a number of useful purposes. In a potentially hostile environment, scientists will have to communicate effectively complex geo-scientific concepts and explain issues such as uncertainty and analytical/diagnostic confidence. They may also have to avoid being drawn into sensitive areas involving societal issues and risk decisions. Risk decision makers will have to demonstrate an understanding of complex hazard scenarios and to explain what risk mitigation decisions they have taken and the reasons for them.

Open and convincing displays of collaboration and agreement between different authorities and key individuals during real crises can build trust with representatives of the media and general public. Panel question and answers sessions involving key personnel, who will have 'communication' roles, can and should be practised during VUSE because it is likely that related training and resource needs will be identified.

The VUELCO Dominica exercise included three very realistic but successful simulated press conferences.

\section{Feedback}

The processes of hazard analysis and hazard communication should be outcome focussed and driven by the expectations and needs of risk decisions and risk decision-makers.

Consideration should be given to measuring the extent to which the exercise and its participants addressed: (1) the needs and expectations of the CPA; (2) the steps, if any, the SAC took to identify those needs and expectations; and (3) the extent to which the SAC satisfied those needs; and identified actions that might lead to improvements.

The VUELCO exercises identified the value of civil protection authorities having an internal technical-scientific structure: (1) to support the SAC in technical analysis (mapping, elicitation, models); and: (2) to improve interactions with the SAC.

\subsection{Observers/Auditors}

\section{Is it necessary to have observers and/or auditors?}

In the VUELCO exercises a very valuable contribution was made by monitors and observers. They can be from the participating organisations or entirely 'independent'. Monitors and observers (particularly with experience of previous exercises and the practices of countries other than the host country) can play a critical role in providing both hot and cold feedback whilst also gaining invaluable personal experience to assist in the planning of future exercises.

VUSE are invariably observed by local and visiting students and early-career geoscience academics. With careful planning, it may be possible for less experienced scientists and civil protection authority decision makers to be involved directly (as happened in the Campi Flegrei VUSE) or indirectly in 'shadow' SAC and CPA teams. The participation of young researchers in this kind of exercise represents a great chance to train future generations of advisory scientists.

\section{What role will be played by nominated observers and auditors?}

Consider whether it would be worthwhile differentiating between: (1) observers who might have responsibility for capturing and presenting immediate unstructured feedback; and (2) auditors who would compile a more formal report possibly in a format and using audit criteria agreed by the main participants in advance.

Would something be gained by having an 'independent' observer/auditor who is not part of any organisation taking part in the exercise?

Independent observers played a very useful role in the VUELCO exercises in Campi Flegrei, Cotopaxi and Dominica and the author was an invited external auditor of the Tenerife exercise.

During the Campi Flegrei exercise, it was recorded that undertaking the role of observer is particularly helpful for senior civil protection authority managers who are thinking of planning an exercise in their own locality. 
Who will be nominated and/or invited to be observers/auditors?

This will depend largely upon the roles which have been chosen and whether some of the observers/auditors should be 'independent'.

\section{Format}

At the end of the exercise will there be a 'hot' feedback session?

The MIAVITA Handbook $(2012,118,179)$ recommends an "on the spot debriefing straight after the exercises with the participants and another one approximately one month later with the exercise organisers, evaluators, observers, and a representative of the general public".

If yes, why, who will lead it and how long will it last?

When and how will the results be recorded, promulgated and acted upon?

Will there be 'cold' feedback meetings, surveys or questionnaires?

If yes, why and who will be responsible for their design and implementation?

When and how will the results be recorded, promulgated and acted upon?

Will a more formal audit of the exercise be undertaken?

If yes, consider whether it might address issues such as the identification of the need for better or additional:

- structures of risk governance

- information sources and resources

- long-term monitoring resources

- consideration of the role of tectonics and resulting faults and features

- geo-history data

- training

- financial, personnel and other resources

- documented procedures

- communication plans and equipment

- media response plans

- easily accessible database catalogues, which may be important and needed urgently during a crisis, of:

- existing data (e.g. seismic, geodetic, gas, water geochemistry and geospatial) and common archiving procedures for newly acquired datasets; and
- information (e.g. geographical information systems 'GIS' digital bases, overlays, metadata, geological maps, remote-sensing images, background levels of unrest indicators, such as seismic energy release rates, normal rates on inflation/deflation, aqueous and geochemistry and fluxes).

- post-exercise actions to review and revise existing procedures in particular those for any future exercises.

\section{Will the observers give real-time feedback} during the exercise?

Consideration should be given to this difficult issue. A balance must be achieved between, on the one hand, unhelpful and intrusive interventions and, on the other, allowing the exercise to proceed in ways that may waste valuable time and/or miss or diminish valuable learning opportunities.

During the Dominica exercise, the three 'independent' observers gave brief feedback to the SAC at the end of Phases 1 and 2 of the exercise. They also gave spontaneous suggestions to the CPA. The participants indicated that they found this helpful and there was clear evidence that suggestions for change were understood and put into practice immediately.

\section{Preparation}

Will instructions be given to the observers/auditors in advance?

Consider giving the observers/auditors a clear brief before the start of the exercise.

Experience from the VUELCO exercises suggests that providing observers with a list of more specific considerations, to include within their more general observations, may result in more focussed outputs.

Will instructions be given to the participants in advance of the exercise to facilitate richer feedback?

Consider asking each participant and/or each team (1) to list their main roles, responsibilities and tasks and (2) to keep a written list of needs that would help them accomplish their tasks covering for example better/different information, training, guidance, software, communication 
equipment, other equipment, personnel, and so on. These lists can then be used during the hot and cold feedback sessions.

Will the participants be told in advance about the planned arrangements for observing/ auditing?

If yes, when? Consider whether the pre-exercise briefing pack is the best place to set out the planned arrangements and time table and what might be required from the participants in this regard.

\section{Discussion}

The checklists presented in this chapter are dedicated to the organisers and participants of the five exercises that this chapter has investigated. The checklists record and build upon the successes, experiences, occasional oversights, misjudgements and mistakes of a few in order to provide readily accessible sources of knowledge, learning and inspiration for others.

This chapter has identified a number of themes:

- VUSE are purpose-driven learning/training activities. Vital knowledge is acquired not only during but also before and after each exercise (see Doyle et al. 2015).

- VUSE must have clear recorded goals based upon the needs and expectations of their participants.

- VUSE are complex and require clear and firm leadership, and very careful planning, funding and execution. This finding is supported by the work of Dohaney et al. (2015), which contains very helpful guidance on design and evaluation methods.

- During the 'planning phase', the critical issues of leadership, purpose, scope, duration, type and financing should be considered.

- The mere planning of a VUSE will provide invaluable knowledge of the wider legal and administrative infrastructures in which it is framed.
- The 'logistics' phase will ensure that the execution of the exercise is not undermined by avoidable technical, communication and other related difficulties. The importance of a comprehensive and comprehensible pre-exercise briefing note and exercise plan cannot be overstated.

- A pre-VUSE field trip will serve numerous purposes including those of introducing relevant geographical, geological, cultural and governance histories and providing an opportunity for relationships to develop between the exercise participants.

- VUSE require and depend upon numerous acts of communication between a wide range of stakeholders with a variety of knowledge, expertise, experience, needs and expectations within many types of formal/informal relationships/associations (see Doyle et al. 2015).

- VUSE are not judged in terms of 'success' or 'failure' but rather in terms of whether relevant knowledge has been generated, recorded, considered and utilised.

- Whenever possible, VUSE simulate:

- 'existing' risk governance arrangements, or those being considered for the future, with real policies, processes and people rather than contrived unrealistic governance scenarios and false role-play; and

- volcanic hazard scenarios based upon, and significant within, the context of the host volcano region, which may experience other relevant or related natural hazards such as tectonic and weather-related hazards.

- VUSE provide unique opportunities:

- to address many known challenges including those of inter-scientist deliberation, scientific uncertainty, analytical/ diagnostic confidence, unorthodox/ maverick science sources, hazard communication, and mass media and social networking relations and communications (see Doyle et al. 2015); 
- to test new/prototype risk arrangements and tools, models and protocols for analysis/communication.

- Great care should be taken to ensure that comprehensive feedback and goal-related knowledge can be captured during and after each exercise and disseminated as widely as possible.

\section{Conclusions}

"Practice doesn't make perfect. Practice reduces the imperfection". None of the five exercises considered in this chapter was completely perfect. They involved not only well-intentioned yet imperfect policies and procedures capable of improvement but also dedicated yet not infallible people keen to seek further knowledge, training and experience. Careful analysis of these exercises shows that, as suggested by Doyle et al. (2015), with very careful planning, execution and review, worrisome periods of emerging volcanic unrest and the dynamics of real-time hazard assessments and risk decisions can be simulated for a wide variety of worthwhile purposes.

However this chapter does not attempt to dictate how future exercises must be organised. Based upon a review of the published records of four exercises and the authors' personal experiences of the five further exercises listed in Table 1, it is believed that these lists will assist the organisers of future exercises to meet the specific challenges of the volcanic hazards they face and the societal, political, economic and legal contexts in which difficult and timely risk decisions have to be made.

The authors hope that the checklists will be considered and used, and, above all, improved. Candid feedback from future exercises will ensure that the guidance notes evolve and will be supplemented by the addition of further detailed exercise studies. Will these checklists facilitate more effective future exercises and improve volcanic risk mitigation? This question can be answered only if they are used and relevant evidence is generated within future post-exercise empirical studies.

The Sendai Framework sets ambitious goals for quality standards, learning, knowledge exchange, education and training. The paramount goal of this chapter is to ensure that the pooled experiences of the few, who have had the advantages and privilege of being exercise participants, will be accessible to the widest possible audience, to encourage future exercises and thereby to improve the governance of volcanic risks.

\section{Disclaimer}

The content of this paper reflects the authors' views and not necessarily the opinion of the organisations to which they belong. The authors and their organisations are not liable for any use that may be made of the information contained therein.

\section{References}

Bartolini S, Cappello A, Martin J, Del Negro C (2013) QVAST: a new quantum GIS plug for estimating volcanic susceptibility. Nat Hazards Earth Syst Sci 13, 3013-3-34

Bergs J, Hellings J, Cleemput I, Zurel Ö, De Troyer V, Van Hiel M, Demeere J-L, Claeys D, Vandijck D (2014) Systematic review and meta-analysis of the effect of the World Health Organization surgical safety checklist on postoperative complications. BJS 101:150-158. https://doi.org/10.1002/bjs.9381

Beta T (2011) Master of Stupidity. http://www.goodreads. com/book/show/8542012-master-of-stupidity

Bretton RJ (2014) The role of science in the rule of law. http://expertsinuncertainty.net

Bretton RJ, Gottsmann J, Aspinall WP, Christie R (2015) Implications of legal scrutiny processes (including the L'Aquila trial and other recent court cases) for future volcanic risk governance. J Appl Volcanol 4:18. https://doi.org/10.1186/s13617-015-0034-X 
Dohaney J, Brogt E, Kennedy B, Wilson TM, Lindsay JM (2015) Training in crisis communication and volcanic unrest forecasting: design and evaluation of an authentic role-play simulation. J Appl Volcanol 4:12. https://doi.org/10.1186/s13617-015-0030-1

Donovan A, Oppenheimer C (2012) Governing the lithosphere: insights from Eyjafjallajökull concerning the role of scientists in supporting decision-making on active volcanoes. J Geophys Res 117:B03214. https:// doi.org/10.1029/2011JB0090802012

Donovan A, Oppenheimer C (2014) Science, policy and place in volcanic disasters: insights from Montserrat. Environ Sci Policy 38, 150-161

Doyle EEH, Johnston DM (2011) Science advice for critical decision-making. In: Paton D, Violanti J (eds) Working in high risk environments: developing sustained resilience. Charles C Thomas, Springfield, Illinois, USA, pp 69-92

Doyle EEH, Johnston DM, McClure J, Paton M (2011) The communication of uncertain scientific advice during natural hazard events. N Z J Psychol 40(4):39-50

Doyle EEH, McClure J, Johnston DM, Paton D (2014) Communicating likelihoods and probabilities in forecasts of volcanic eruptions. J Volcanol Geoth Res 272 (2014):1-15

Doyle EEH, Paton D, Johnston DM (2015) Enhancing scientific response in a crisis: evidence-based approaches from emergency management in New Zealand. J Appl Volcanol 4:1. https://doi.org/10.1186/ s.13617-014-0020-8

Errington EP (1997) Role-play. Higher education research and development society of Australasia, Jamison Centre, ACT

Errington EP (2011) Mission possible: using near-world scenarios to prepare graduates for the professions. Int $\mathrm{J}$ Teach Learn High Educ 23:84-91

Fiske R (1984) Volcanologists, Journalists, and the Concerned Local Public: a tale of two crises in the Eastern Caribbean. In: Explosive volcanism: inception, evolution and hazards. Geophys. Study Committee, National Research Council, National Academy Press, Washington, pp 170-176

Galanti E, Goretti A, Foster B, Di Pasquali G (2006) Geotech Geol Earthquake Eng 369-384

Gawande A (2010) The checklist manifesto-how to get things right. Profile Books Ltd, London

Harris AJL, Gurioli L, Hughes EE, Lagreulet S (2012) Impact of Eyjafjallajökull ash cloud: a newspaper perspective. J Gepphys Res 117:35. https://doi.org/10. 1029/2011JB008735

Hincks TK, Jean-Christophe Komorowski J-C, Sparks SR, Aspinall WP (2014) Retrospective analysis of uncertain eruption precursors at La Soufrière volcano, Guadeloupe, 1975-77: volcanic hazard assessment using a Bayesian Belief Network approach. J Appl Volcanol 2014(3):3. https://doi.org/ 10.1186/2191-5040-3-3
Hood C (1986) Administrative analysis: an introduction to rules, enforcement and organisations. Wheatsheaf Books, Sussex

Hood C (2011) The blame game-Spin, bureaucracy and self-preservation in government. Princeton University Press, Princeton, New Jersey, USA and Woodstock, Oxfordshire, UK

IAVCEI (2015) News no. 1-3. http://www.iavcei.org/

International Federation of Red Cross and Red Crescent Societies (IFRC) and United Nations Development Programme (2015) The checklist on law and disaster risk reduction, Pilot version, March 2015. IFRC, Geneva, Switzerland

Jenkins S, Spence R, Baxter P, Komorowski J-C, Sara Barsotti S, Esposti-Ongaro T, Neri A (2012) Preparation of disaster risk scenarios at $\mathrm{La}$ Soufriere, Guadeloupe poster at volcanic and magmatic studies group annual meeting 2013

Johnston D, Scott B, Houghton B, Paton D, Dowrick D, Villamor P, Savage J (2002) Social and economic consequences of historic caldera unrest at the Taupo volcano, New Zealand and the management of future episodes of unrest. Bull NZ Soc Earthquake Eng 35 (4):215-229

Jordan TH, Chen Y.-T, Gasparini P, Madariaga R, Main I, Marzocchi W, Papadopoulos G, Sobolev G, Yamaoka K, Zschau J (2011) Operational earthquake forecasting: state of knowledge and guidelines for implementation, findings and recommendations of the international commission on earthquake forecasting for civil protection, submitted to the Department of Civil Protection, Rome, Italy. Ann Geophys 54, 4. https://doi.org/10.4401/ag-5350

Lipshitz R, Klein G, Orasanu J, Salas E (2001) Focus article: taking stock of naturalistic decision making. J Behav Decis Mak 14(5):331-352

Marrero JM, García A, Llinares Á, Berrocoso M, Ortiz R (2015) Legal framework and scientific responsibilities during volcanic crises: the case of the El Hierro eruption (2011-2014). J Appl Volcanol 4:13. https:// doi.org/10.1186/s13617-015-0028-8

Marzocchi W, Newhall C, Woo G (2012) The scientific management of volcanic crises. J Volcanol Geoth Res. https://doi.org/10.1016/j.volgeorgres.2012.08.016

McGuire WJ, Kilburn CRJ (1997) Forecasting volcanic events: some contemporary issues Geo. Rundsch 86:439-445

MIAVITA (Mitigate and Assess risk from Volcanic Impact on Terrain and human Activities) (2012) Handbook for volcanic risk management: prevention, crisis management, Resilience, MIAVITA team, Orleans. http://miavita.brgm.fr/default.aspx

Mothes PA, Yepes HA, Hall ML, Ramón PA, Steel AL, Ruiz MC (2015) The scientific-community interface over the fifteen-year eruptive episode of Tungurahua Volcano, Ecuador. J Appl Volcanol 4:9. https://doi. org/10.1186/s13617-015-0025-y 
Newhall CG (2010) A checklist for volcanic risk mitigation. Cities on volcanoes 6 presentation, earth observatory of Singapore

Newhall C, Aramaki S, Barberi F, Blong R, Calavache M, Cheminee J-L, Punongbayan R, Siebe C, Simkin T, Sparks RSJ, Tjetjep W (1999) International association of volcanology and chemistry (IAVCEI) subcommittee for crisis protocols - professional conduct of scientists during volcanic crises. Bull Volcanol 60:323-334

NZ/MCDEM (2008) Exercise Ruaumoko 2008: final exercise report. Ministry of Civil Defence \& Civil Management, Wellington, NZ

OECD (2015), Scientific advice for policy making: the role and responsibility of expert bodies and individual scientists. OECD science, technology and industry policy papers, no. 21, OECD Publishing, Paris. http:// dx.doi.org/10.1787/5js3311jcpwb-en

Paton D, Jackson D (2002) Developing disaster management capability: an assessment centre approach. Disaster Prev Manage 11(2):115-122

Renn O (2008) Risk governance - coping with uncertainty in a complex world. Earthscan, London, New York

Ricci T, Nave R, Barberi F (2013) Vesuvio civil protection exercise MESIMEX: survey on volcanic risk perception. Ann Geophys 56(4):s0452. https://doi. org/10.4401/ag-6458

Ronan KR, Johnston DM, Daly M, Fairley R (2008) School children's risk perception and preparedness: a hazard education survey. Aust J Disaster Trauma Stud 1. ISSN: 1174-4707. Available at: http://www.massey. ac.uk.nz/ trauma/issues/201-1/ronan.htm

Rothstein H (2002) Neglected risk regulation: the institutional attenuation problem, centre for analysis of risk and regulation. London School of Economics and Political Science, London

Salas E, Stout RJ, Cannon-Bowers JA (1994) The role of shared mental models in developing shared situational awareness. In: Gilson RD, Garland DJ, Koonce JM (eds) Situational awareness in complex systems: proceedings of a cahfa conference. Embry-Riddle Aeronautical University Press, Daytona Beach, FL, pp 298-304

Sandri L, Guidoboni E, Marzocchi W, Selva J (2009) Bayesian event tree for eruption forecasting (BET_EF) at Vesuvius, Italy: a retrospective forward application to the 1631 eruption Bull. Volcanol 71:729-745

Sobradelo R, Bartolini S (2014) Marti J (2014) HASSET: a probability tool to evaluate future volcanic scenarios using Bayesian inference. Bull Volc 76:770
Solana MC, Kilburn CRJ, Rolandi G (2008) Communicating eruption and hazard forecasts on Vesuvius, Southern Italy. J Volcanol Geoth Res 189(2010):308-314

Sparks RSJ, Aspinall WP, Auker M, Crosweller S, Hincks T, Mahony S, Nadim F, Polley J, Syre E (2012a) Mapping and characterising volcanic risk, magmatic rifting and active volcanism conference, Addis Ababa, 12 Jan 2012

Sparks RSJ, Aspinall WP, Auker M, Crosweller S, Hincks T, Mahony S, Nadim F, Polley J, Syre E (2012b) Volcano hazard and exposure in global facility for disaster reduction and recovery priority countries and risk management measures, GVM 1st workshop 30 Apr 2012, University of Bristol and NGI Norway for the World Bank

Treadwell JR, Lucas S, Tsou AY (2014) Surgical checklists: a systematic review of impacts and implementation. BMJ Qual Saf 23:299-318. https://doi.org/ 10.1136/bmjqs-2012-001797

UN/ISDR (2015) Sendai framework for disaster risk reduction 2015-30

van Ments M (1999) The effective use of role-play: practical techniques for improving learning. Konan Page Ltd, London

Woo G (2008) Probabilistic criteria for volcano evacuation decisions. Nat Hazards 45:87-97. https://doi.org/ 10.1007/s11069-007-9171-9

\section{Further reading sources on VHUB website}

\section{VUELCO resources}

Colima Exercise Plan

Colima Debriefing Report

Ciolli S, De la Cruz-Reyna S (2013) Colima volcano exercise debriefing report. https://vhub.org/resources/2477

Campi Flegrei Simulation Plan

Campi Flegrei Simulation Debriefing Report

Ciolli S, Cristiani C, Golisciani GA (2014) VUELCOCampi Flegrei Caldera unrest scientific simulationdebriefing report. https://vhub.org/resources/3640

Cotopaxi Debriefing Report

Dominica Exercise Plan

Dominica Exercise Debriefing Report

Ciolli S, Robertson REA (2015) VUELCO_Dominica exercise debriefing report. https://vhub.org/resources/ 3822 
Open Access This chapter is licensed under the terms of the Creative Commons Attribution 4.0 International License (http://creativecommons.org/licenses/by/4.0/), which permits use, sharing, adaptation, distribution and reproduction in any medium or format, as long as you give appropriate credit to the original author(s) and the source, provide a link to the Creative Commons license and indicate if changes were made.
The images or other third party material in this chapter are included in the chapter's Creative Commons license, unless indicated otherwise in a credit line to the material. If material is not included in the chapter's Creative Commons license and your intended use is not permitted by statutory regulation or exceeds the permitted use, you will need to obtain permission directly from the copyright holder. 